\title{
Corela
}

Cognition, représentation, langage

11-1 | 2013

Vol. $11, \mathrm{n}^{\circ} 1$

\section{Symmetric structures}

\author{
Isabelle Haïk
}

\section{OpenEdition}

Journals

Édition électronique

URL : http://journals.openedition.org/corela/2875

DOI : 10.4000/corela.2875

ISSN : 1638-573X

\section{Éditeur}

Cercle linguistique du Centre et de l'Ouest - CerLICO

\section{Référence électronique}

Isabelle Haïk, «Symmetric structures », Corela [En ligne], 11-1 | 2013, mis en ligne le 01 juillet 2013, consulté le 01 mai 2019. URL : http://journals.openedition.org/corela/2875 ; DOI : 10.4000/ corela.2875

Ce document a été généré automatiquement le 1 mai 2019.

\section{(c) (i) (2)(2)}

Corela - cognition, représentation, langage est mis à disposition selon les termes de la licence Creative Commons Attribution - Pas d'Utilisation Commerciale - Partage dans les Mêmes Conditions 4.0 International. 


\title{
Symmetric structures
}

\author{
Isabelle Haïk
}

\section{Face to face and student after student}

1 Jackendoff (2008) gives the following illustrations of NPNs:

(1) face to face, hand over hand, hand in hand, arm in arm, day by day, dollar for

dollar, student after student, book upon book

2 However, there are two constructions to distinguish. ${ }^{1}$ Some of the examples above are lexical small clauses, the face-to-face construction, and the others are lexical coordinate structures, the student-after-student construction. By "lexical", I mean that the element is formed by rules of morphology. It is a word in the traditional view that distinguishes morphology and syntax, an item that is a zero-level form in syntax, namely the smallest unit that syntax works with. ${ }^{2}$

(2) the face-to-face construction (lexical small clause) face to face, hand over hand, hand in hand, arm in arm, day by day, dollar for dollar

(3) the student-after-student construction (lexical coordinate noun) student after student, book upon book

We will consider the two constructions in turn, but as a starting-point, let us focus on the properties that are shared by the two constructions. These examples and generalizations are from Jackendoff (2008). First, the nouns must be the same:

(4) case for case/*ase for example

(5) face to face $/{ }^{*}$ face to nose

Second, they may not have determiners nor, most often, plural nouns, even if the interpretation is that of a plurality:

(6) a. *the man for the man

b. *soldier's father for soldier's father

c. *men for men, *books after books, *weeks by weeks

5 The identity requirement on the nouns will be explained in section 6, with apparent counterexamples, like head to toe or boy to man, and head to tail, discussed in section 4 . 
6 As for the second set of properties, illustrated in (6), they show that the NPN constructions are morphological constructs, which is the place where we will start.

\section{NPNs are lexical}

7 The properties illustrated in (6) are properties of words. As discussed in Williams's work, for instance Williams (1981), words cannot be formed with phrases, so they may not have determiners, as in (7a). ${ }^{3}$ As for the plural marker, Ns in compounds which are interpreted as plural most often do not and may not bear the plural morpheme, as in (7b), something that is impossible in syntax, where count nouns must be plural if they refer to pluralities. ${ }^{4}$

(7) a. *a the Bible-lover (meaning 'a lover of the Bible')

b. *books-lover, *candies-giving, *oranges juice

Word-formation rules have these properties, so it is probable that NPNs are words. I provide an account of these words in section 7, but before that, let us distinguish the two structures.

\section{The lexical absolute construction face to face}

9 Absolute constructions are small clauses which act as modifiers. Some are verbal modifiers, as in (8), and others nominal ones, often complements of the P with, as in (9ac):

(8) Fog all over the place, they had a hard time finding their way.

(9) a. I found him with his hands up.

b. They stood there, (with) their eyes lowered.

c. He raised his eyes, (with) his mind racing.

Lots of small clause NPNs, such as face to face, are nominal modifiers, but some, like $\mathrm{N}$ by $\mathrm{N}$ or $\mathrm{N}$ for $\mathrm{N}$ (step by step, line for line) are verbal modifiers. In this article, we will study in more detail nominal modifiers, so let us start with (9). Such constructions are the descriptions of the posture (physical, or, by metaphor or metonymy, mental) of animates. By describing a part of his/her body, they name the posture of the referent of the DP, and thus indirectly qualify that referent. In French, absolute constructions are not introduced by the preposition avec 'with', contrary to English. If NPNs, which do not have with either, are absolute constructions, then the French construction may lead us to an accurate account of NPNs, which we now proceed to consider.

We should distinguish two classes of small clauses describing body-parts, those that describe a physical quality of the body-part and those that denote a temporary position in space of the body-part. For example, only those that denote temporary positions may occur as predicates of small clauses under exceptional case-marking verbs:

(10) *Je le croyais les yeux bleus. ${ }^{5}$

I him believed [ the eyes blue $]_{\mathrm{SC}}$

'I believed him with blue eyes: I believed he had blue eyes.'

(11) Je le croyais les mains levées.

I him believed [ the hands up $]_{s c}$

'I believed him with his hands up.'

12 Given that all face-to-face NPNs denote transitory postures, we will guide our research with the latter kind of French absolute small clauses. 

are canonically constructed with predicative APs. If absolute constructions indeed are modifiers, we may wonder whether they may occur in those AP positions. They may not under the verbs meaning 'seem' and 'become'. Whereas the verbs se tenir 'stand' and rester 'remain' may: 6

(12) a. *Albert semble/paraît/est devenu les mains levées.

Albert seems /looks/became the (his) hands up

b. Albert se tenait/est resté les mains levées

'Albert stood/remained the hands raised

The other places in which one may find modifiers is that of the predicate of a small clause or as a modifying manner adjunct or a nominal postmodifier, namely, all the positions in which there is modification, apart from the positions dependent on a predicative verb like seem or become. All these syntactic positions accept absolute small clauses, a conclusion also reached in Hanon (1989)'s thorough study:

(13) a. Je l'ai trouvé les mains en l'air.

I him have found the hands up

'I found him with his hands up.'

b. Il l'attendait, les bras croisés.

He her was waiting, the arms crossed

'He was waiting for her, his arms crossed.'

c. On l'a conduit les yeux bandés.

They him have led the eyes blindfolded

'He was led blindfolded.'

d. Ils sont partis (la) main dans la main.

They are left (the) hand in the hand

'They left hand in hand.'

e. On l'a posé les pieds par terre.

They him have put the feet on ground

'They put him with his feet on the ground.'

f. Il se tenait les bras croisés.

He was standing the arms crossed

'He was standing with his arms crossed.'

g. ?Ceux les bras croisés n'ont rien dit. ${ }^{7}$

Those the arms crossed NEG have nothing said

'Those with their arms crossed did not say anything.'

dition to its meaning as a modifier, the English face-to-face construction has exactly the distribution of French absolute small clauses. It may not occur in the position of elements dependent on a predicative verb like seem and become and it may under stand and remain: ${ }^{8}$

(14) a. ${ }^{*}$ They seem/appear/became face to face.

b. They stood/remained face to face a long time.

It appears in the positions of nominal modifiers and in positions of expressions of manner:

(15) a. They stood hand in hand.

b. Nose against nose, they were looking at each other.

c. They walked along arm in arm.

d. Back-to-back performances. 

like their syntactic correlates prisoner of a war, down to the earth, etc. In Romance compounds, there is a P-unit formed of a P and a complement $\mathrm{N}$, like to earth in down to earth. If that P-unit is a complement, then it occurs to the right of the head that takes it as a complement, like to earth in down to earth or for-all in free-for-all. That P-unit may also function as a predicate, as in compounds like face contre terre 'face against earth' (21d below) or man-at-arms (19 above)), in which the word on the left of the P-unit is interpreted as its subject. A syntactic small clause is a constituent formed of a phrase having a subject (Stowell 1983, Williams 1980, Rothstein 1983). ${ }^{11}$ We may then suppose that small clause NPNs are derived like man-at-arms. For example, a form like hand in hand 
could be analyzed as a Romance compound with hand on the left as a subject and in hand the predicate. I will eventually hypothesize for a slightly different analysis of the NPN constructions, but before that, let us investigate the possibility that the P-unit is a predicate. Let us consider a number of forms that seem to conform to the Romancecompound analysis:

(21) a. head to toe, boy to man, floor to ceiling (oak shelves), hand-to-mouth

b. tongue-in-cheek, head over heels, hand over fist, cul par-dessus tête ('ass over

head')

c. head to tail (trucks and semis)

d. face contre terre ('face against earth')

e. un tête à queue (lit: 'a head to tail' = '(a) slew around')

Those illustrated in (21a), following Williams (1994a), are presumably interpreted as with a silent from, which is optional but possible (from) head to toe, (from) boy to man, (from) floor to ceiling, (from) hand to mouth. That preposition takes the first $\mathrm{N}$ as its complement, not the whole NPN, so they have the structure illustrated in (22a), not a subject-predicate structure. They will not concern us. Those in (21b) are absolute constructions with two body-parts of one individual; some of these NPNs may be complements of the preposition with, for example, with [tongue in cheek] $]_{s c}$. The forms in (21c) describe two body-parts belonging to two different individuals and they imply multiplicity of individuals, like the $N$ after $N$ construction. The form in (21d) describes an individual's body-part in space, and that in (21e) involves two body-parts of one individual and is a noun. Now, given that all these examples except (21a) apparently have the form of Romance compounds, we may reasonably think that they are outputs of Romance-compound formation, as in (22b):

(22):
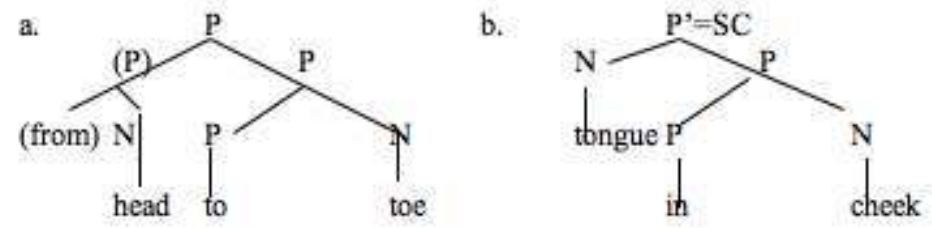

This is supported by the fact that these forms have the compositional meaning that one expects. For instance, tongue in cheek literally means that one's tongue is in one's cheek. Then, by the metonymy that names a feeling in naming the gesture that goes with that feeling (frownat, for instance), this idiom means that one is having a superior attitude.

One important question for the present article is that, if Romance-compound formation is responsible for forms like (21d-e), then it could also be responsible for the NPN construction in general. I will propose that the NPN construction is not a Romance compound, based on a particular property of the data, the difference of productivity between NPNs with identical Ns and those with different Ns.

As a Romance language, French has lots of Romance compounds:

(23) pas de porte 'key money', garde-à-vous '(standing to) attention', pierre à feu 'flint'

That could be coincidental, but note that locative prepositions are rare in Romance compounds and that the prepositions that most often relate the two heads are $a$ 'to' and de 'of', whereas the NPN face-to-face construction has locative prepositions. As for NPNs, for the most part, they involve body-parts. The relevant fact is that forms with bodyparts like (21b), cul par-dessus tête, when the Ns are different, are quite rare. However, 
NPNs with identical Ns are numerous, like nez à nez 'nose to nose', face à face 'face to face', pied à pied 'foot to foot', and they are fully productive with the preposition contre, with which any $\mathrm{N}$ is possible:

(24) Mettez-vous vertèbre contre vertèbre, dos contre dos, nez contre nez, etc.

Place yourselves vertebrae against vertebrae, back against back, nose against nose are binary branching. If we assume that syntax is a reflex of semantic and morphological composition, then syntax is not an autonomous component of grammar but it is a reflex of derivation as a stepwise series of mental operations combining various elements with one another. Binary branching reflects the combination of elements two at a time. Jackendoff (2006) has claimed that there is no logical necessity for binary branching, and that sentences could have, for instance, a flat structure, but it seems more interesting to assume that syntax is a by-product of semantic composition, scope-assignment and 
feature-checking, because then it reveals what mental operations are effected in forming sentences, or merely reveals that it results from computation, as claimed in the present article. $^{14}$

Suppose that semantic or morphological composition is a task that cannot be computed in a ternary fashion. This means that ternary branching in syntax or the lexicon is impossible due to the properties of semantic calculus and feature checking. ${ }^{15}$ Importantly, that makes the ban on multiple branching inviolable, since it pertains to our cognitive capacities.

If NPN constructions were synthetic compounds, then they should have a ternary structure, with the subject face and the object face merged with to and processed with it at the same time, violating the cognitive constraint on ternary structures. But there exists one way that the brain arrives at a ternary structure.

\section{Symmetry and cognition}

41 Let us make two remarks about the face-to-face expression. It is striking, first, that this construction forces the nouns to be the same, and second, that it describes a symmetric spatial relation between two body-parts, in which one body part is the mirror image of the other.

42 For lots of prepositions entering the NPN construction, like to, by and in (face to face, back to back, side by side, arm in arm, etc.), the plane of symmetry is preferred when it is vertical, meaning that the bodies must be standing. For example, hand in hand applies properly when the plane of symmetry of the two hands is vertical. According to my personal judgment for French, face à face 'face to face', can hardly be used if one's face is on top of the other, with two people lying, in which case the plane of symmetry would be horizontal. This could be due to meaning requirements on spatial prepositions in general, but verticality is the direction that is the most salient in perceptual vision (van der Helm and Leeuwenberg 1996), and we may presume that this has been relevant in the creation of NPNs. Contre 'against', which is productive in the NPN construction, does not force the bodies to be vertical. So, fighters may be visage contre visage 'face against face', even if they are in a lying position, so the vertical direction of the plane of symmetry is not a necessity of the construction, but a preference.

We have to explain why the lexicon may contain a ternary structure like NPN, whereas computation only allows pairing. This concerns the speaker's grammar, so speech production, rather than speech analysis. We thus have to consider tasks rather than perception. In perception, symmetry is favored, more so with mirror symmetry than repetition symmetry, and its goodness can be measured (van der Helm and Leeuwenberg 1996). As for task production, the easiness or naturalness of symmetry may be tested for instance with bimanual tasks. Cattaert, Semijen and Summers (1999)have shown that the task of drawing circles with the two hands in the horizontal plane is easy to perform under the symmetrical mode of coordination, whereas asymmetry gives rise to large distortion of the hand trajectory and hand coordination. For instance, they say that in making fast asymmetrical movements, the hands show increased phase difference and phase variability, as well as transitions to symmetrical movements, and cases of frequency decoupling. Personal experience ties up with these results. For instance, if we try and draw synchronically with our two hands mirror figures on each part of a vertical 
line, we feel that the task is easy, as easy if not easier as drawing with our non dominant hand. We can compare this task with that of synchronically drawing different figures, or the same figures but not in mirror symmetry, or non synchronically mirror figures or non symmetrical figures, etc. ${ }^{16}$ Anything that departs from synchronic mirror symmetry is hard, whereas synchronic mirror symmetry is easy. ${ }^{17}$ Moreover, personal observation tells us that when we draw a line, a circle or anything else under the mode of symmetry, we do not need to concentrate on the two drawings, though we produce two drawings.

Now, let us return to the formation and interpretation of the NPN structure. Jackendoff (2008) has very interestingly come to the conclusion that NPN is produced by starting with a doublet and not a triplet. According to him, the numeration of NPN is $\{N, P\}$, and that form is realized as NPN by reduplication of the N. The idea that the numeration is the $\{\mathrm{N}, \mathrm{P}\}$ doublet is appealing; it is a strong claim that explains why the Ns must be the same in this construction. However, it does not say why this should be so. In the present cognitive account, I borrow Jackendoff's claim that the numeration of the NPN construction is $\{\mathrm{P}, \mathrm{N}\}$. This means that we work mentally with two objects only. What happens is that $\mathrm{P}$ merges symmetrically and synchronically on two sides of the $\mathrm{N}$, in one single mental operation. It projects two predicative P-units through symmetry, namely PN on the right-hand side and NP on the left-hand side. This produces a ternary structure.

The assumption I am making here is that, in a flat ternary structure, one $\mathrm{N}$ may be defined as a sister, here a subject, of the block formed with the other two elements $\mathrm{P}$ and $\mathrm{N}$, let us call it a P-unit, because it is not belong to that group and no node intervenes between it and that group. Moreover, I assume that, because of symmetric production and computation, such a structure reads both ways, left to right and right to left. So, the $\mathrm{N}$ merged to the left of the $\mathrm{P}$ is interpreted as the subject of $\mathrm{PN}$, and the $\mathrm{P}$ on the right as the subject of $\mathrm{PN}$, yielding the reciprocal reading ' $\mathrm{N}_{1} \mathrm{PN}_{2}$ and $\mathrm{N}_{2} \mathrm{PN}_{1}$ ': hand in hand means 'John's hand is in Mary's hand and Mary's hand is in John's hand. ${ }^{18}$

As for the symmetric meaning, it is a necessary result of symmetric merging. Iconicity here, in which symmetry of form is associated with symmetry in meaning, is not a theoretical prerequisite, but it is derived. All words and phrases give rise to mental representations. Given that the Ns that occur on both sides of the preposition are the projections of one and the same element, $\mathrm{N}$, and given that $\mathrm{N}$ summons the mental representation of one particular object, $\mathrm{N}$ gives rises to two distinct but twin mental representations, one associated with the $\mathrm{N}$ before the $\mathrm{P}$ and the other with the $\mathrm{N}$ after the $P$. The meaning of the $P$ will say whether the mental representations of the two Ns should be set in mirror symmetry or in sequential symmetry. Sequential symmetry is another possibility of representing objects in symmetry through a plane, and it yields the student after student construction, $\mathrm{N}$ by $\mathrm{N}$, and expressions like head to tail, nose to tail, bumper to bumper, etc. Sequential symmetry involves multiple referents.

We thus conclude that the NPN constructions are the result of a mental operation of structure production involving two linguistic objects, $\mathrm{P}$ and $\mathrm{N}$, effected as symmetric merging, necessarily accompanied with the meaning of symmetry of the things named, whose spatial relation is described by the $\mathrm{P}$. 


\section{Static and dynamic NPNs} not idiosyncratic and receives an explanation. First, when the small clause is headed by for, the things named by the Ns do not have to be body-parts, so the body-part requirement does not always hold. The observed restrictions derive from the fact that the NPN has to fit semantically with its context, like any ordinary phrase or word. As mentioned earlier (section 4), absolute constructions may be verbal or nominal modifiers. When an absolute construction bears on the verb, it is a small clause with the interpretation of a manner adverb. For instance, $\mathrm{N}$ for $\mathrm{N}$ conveys the meaning of pairing the referents of the nouns. It is thus expected that the $\mathrm{N}$ for $\mathrm{N}$ requires verbs or nouns in its linguistic context congruent with this meaning, like exchange, translate, match, translation, etc., and why there is no requirement on the $\mathrm{N}$ in that case, given that anything can be compared or exchanged. But when NPN acts as a DP modifier, it does so through the description of a body-part of the referent of the DP, like nominal absolute constructions in general. So, it will have to contain a body-part. ${ }^{19}$

\section{The student-after-student construction}

The student-after-student construction is a coordinate lexical structure. The expression student-after-student illustrates NPNs whose preposition indicates succession, either in space or in time, and I claim that, similarly to the traditional view on syntactic coordination, it is not the P that heads the construction, but the $\mathrm{N}^{20}$ Jackendoff (2008) has 
noted that the only prepositions allowed to form such coordinate constructions are after and upon. ${ }^{21}$ So, NPNs like house after house, time after time, book upon book, etc. are nominal, not prepositional, and thus they have nominal functions:

(31) Student after/upon/*by student flunked.

\section{Complementation and adjectival modification} will be explained owing to the kind of structure obtained by symmetry, to the nature of the head of the NPN form, and to the hypothesis that syntax has access to the structure of NPN in English.

First, all NPNs, face-to-face and student after student, may be modified by an adjective. In that case, the scope of the adjective spreads onto the two Ns (some examples from Jackendoff 2008):

(33) a. day by/after miserable day

b. step by dazed step (In the Woods, p. 99, Tara French)

c. He held me nose to bleeding nose and hissed a final warning. (internet source)

d. [...] her young students are face to smiling face with a hometown example

entrepreneurship! (internet source)

60

This is reminiscent of coordinate structures with their across-the-board effect, in which a single surface element is interpreted inside the two coordinates (cf. across-the-board extraction, Ross 1967, Goodall 1984 and Williams 1978). Modification in syntax has the same across-the-board property:

(34) the angry boys and girls 
61

Goodall (1984) has claimed that coordinate structures are unions of phrase-markers. They form parallel structures, that is to say, structures represented on distinct planes, with possibly a number of shared nodes. For instance, Goodall represents wh extraction as the union of two parallel phrase-markers sharing the fronted element:

(35) Which piece of music does Henri like and Mary hate?

which piece of music does

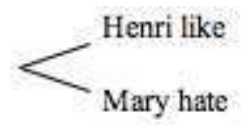

If, as in this article, we assume that syntax is a reflex of processing, saying that structures are parallel means that, at some point of their derivation, the two coordinates are computed together simultaneously, possibly subject to operations which take both structures as inputs, yielding across-the-board representations and interpretations. Now, symmetric structures too are parallel structures because in an NPN form, the two Ns are computed at the same time with the P. Spelling stipulates that they must linearize as P-NP.

Let us consider what happens formally when $\mathrm{N}$ is modified. I have to make two assumptions. The first one is that syntax may look into the NPN forms in English, even though I have qualified them as words. This violates the principle of lexical integrity of Postal (1969), discussed in Bresnan and Mchombo (1995). In this article, I will simply assume that English permits it. ${ }^{23}$ The second assumption aims to account for the position of the adjective. I will assume that, in symmetry, we may talk of a dominant side, and that in the symmetric merging process of $\mathrm{P}$ and $\mathrm{N}$, the right-hand side $\mathrm{N}$ is dominant. For that reason, it must obey the left-to-right order of the probe-to-target relation. And the lefthand side $\mathrm{N}$ is the one obtained freely from symmetry, and it is not subject to that order requirement (cf. footnote 13). That entails that the right-hand side $\mathrm{N}$ belongs to the structure of the clause. It is thus on the same plane as the whole clause, whereas the other $\mathrm{N}$ belongs to another plane. Consider the structure of an NPN modified by an adjective, in which the linear order of spelling of an NPN form (an N on each side of the P) must be respected. I indicate in bold the $\mathrm{N}$ that is not on the plane of the clause:

(36)

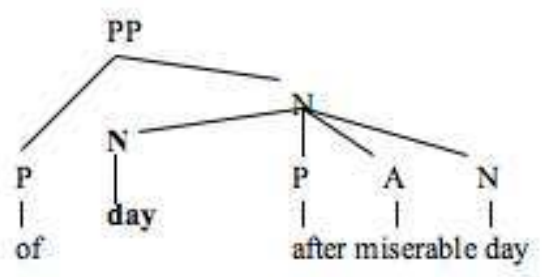

(Jerry suffered months)

The lexicon produces day after day, and that ternary structure comes into syntax, accessible to syntax in English by assumption. As an attributive adjective, A has to merge with N. Given that A belongs to the clause, it must merge with the $\mathrm{N}$ that is on the plane of the clause, namely the right-hand side N. Modification is done under sisterhood, so it merges as a sister of the right-hand side $\mathrm{N}$. The position which yields a good result with respect to other conditions is the one shown in the tree above. There, the ternary structure makes the adjective take semantic scope over the two Ns it is a sister of. The sisterhood relation is clear for the right-hand side $\mathrm{N}$ : neither node is contained in the other and no node intervenes, either structurally or linearly, between them. Considering 
the first $\mathrm{N}$, the $\mathrm{A}$ is a sister of $\mathrm{N}$ because the representation of this $\mathrm{N}$ on a different plane than that of the clause allows the $\mathrm{P}$ not to linearly intervene between the two elements. The $\mathrm{A}$ and the first $\mathrm{N}$ form an independent plane, on which they are sisters, so that structure is an instance of modification of the $\mathrm{N}$ by the A. Consequently, in such a structure, the A is in a modifying position with respect to the two Ns, explaining, first, why this interpretation is possible, and second, why it is obligatory. No branches cross, and spelling respects the order N-P-N.

I repeat that, in the symmetric mode of production of the structure, the first $\mathrm{N}$ is on a different plane than that of the clause, and the second $\mathrm{N}$ is entirely part of the clause and belongs to the plane of the clause. This hypothesis explains why the adjective may not occur before the first $\mathrm{N}$ :

(37) *Jerry suffered months of miserable day after day

This string of words is such that the position of the adjective should be somewhere before after. But that is not a licit position of the adjective on the plane of the clause, where the $\mathrm{A}$ is licenced by no N. Given that the P linearly intervenes between the A and the right-hand side $\mathrm{N}$, the $\mathrm{A}$ cannot be licensed by its relation with that $\mathrm{N}$ :

(38)

\section{(Jerry suffered months)}

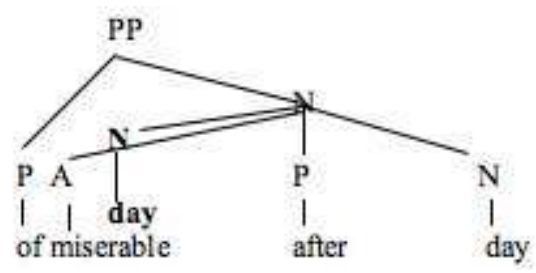

67 There is one exception to the observation that the first $\mathrm{N}$ cannot be modified. The first $\mathrm{N}$ may in fact be modified by an adjective, but in that case, first, each $\mathrm{N}$ must be modified, and, second, the adjectives must be the same:

(39) Jerry suffered months of miserable day after miserable day.

(40) *Jerry suffered months of terrible day after miserable day.

68 As seen earlier, it is impossible for an adjective to occur in the position shown above, (38). Forms with identical adjectives escape from ill-formedness because the first adjective is projected in the mode of symmetry, like the $\mathrm{N}$ it modifies. Modification occurs in the lexicon, which produces an AN noun, miserable day. This noun merges with the $\mathrm{P}$ with symmetry, yielding two occurrences of miserable day on each side of the $P$.

To conclude, the puzzling position of the adjective in NPN constructions confirms the idea that they are special kinds of constructions. The student after student construction is a coordinate noun, so it seems close to a syntactic coordination of two Ns, like boys and girls, but it is not the same. As shown below, the adjective occurs before this coordinate head, because both Ns are coordinated in syntax, forming an N, which is the target of the relation with the A. So the A merges with that $\mathrm{N}$ :

(41)

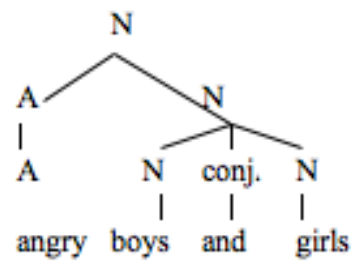


70 I have illustrated the merging of the adjective with coordinate NPNs, like student after student, but small clause NPNs like face to face or step by step permit adjectival modification too. That is because the adjective may merge as a sister to $\mathrm{N}$ in that case too, sister in a flat structure meaning that no node contains the other and no node intervenes between the two:

(42) step by dazed step

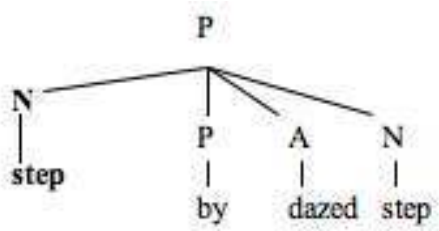

71 It does not matter that the head of NPN is P. Given the hypothesis that A has access to the NPN structure, and because of the flat structure, the A may merge as a sister of any of the nodes. It may thus merge as a sister to $\mathrm{N}$ in the position that yields a well-formed acrossthe-board modification.

72 Let us now see what happens with complementation. NPNs may have complements, but only coordinate NPNs, not small clauses:

(43) a. They suffered day after day of unending rain (coordinate NPN)

b. Layer (up)on layer of mud lay on the seabed. (coordinate NPN)

(44) ${ }^{*} \mathrm{He}$ figured it out step by step of giant. (small clause NPN) ${ }^{24}$

In coordinate NPNs, the complement is interpreted across the board. The structure is as follows:

(45)

they suffered

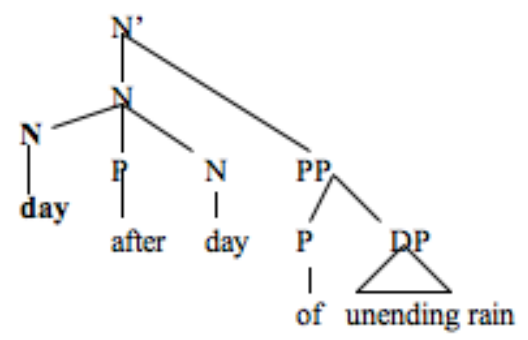
NPNs:

(46) ${ }^{*}$ He figured it out step by step of

$$
\text { he figured it out }
$$

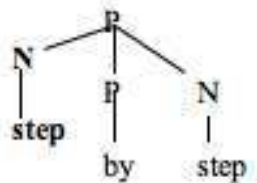

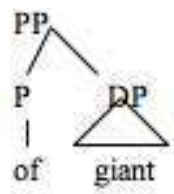

This structure is one in which the NPN enters the syntax, with the complement not yet merged. We see that there is no way to form an $\mathrm{N}$ ' between either $\mathrm{N}$ and the PP 
complement. The complement should merge with the $\mathrm{N}$, and produce a projection of $\mathrm{N}$, but the $\mathrm{N}$ is not a projecting category here, $\mathrm{P}$ is, so it cannot take a complement.

But things are not not that simple, there are counter-examples to the claim that small clause NPNs cannot take complements:

(47) a. Does my default profile on the billing.perfectworld site have to match line

for line of the given information used on PayPal? (internet source)

b. The commentary, running almost line for line of the text, enables Le. Boulluec

to display his extensive knowledge ... (internet source)

I will assume that these structures are identical to the complementation of complex prepositions like outside of, or in front of, which are composed of a $\mathrm{P}$ with an $\mathrm{N}$ complement, forming a unit (outside, in front) and in which the complement of that unit acts like the complement of the noun (side, front) in being introduced by the genitive preposition, though prepositions usually take direct complements. This means that forms like line for line of are cases in which line for line is reanalyzed as a complex element taking a genitive complement because of the nouns line. If that is the right analysis, the genitive complement merges with the $\mathrm{P}$ line for line:

(48)

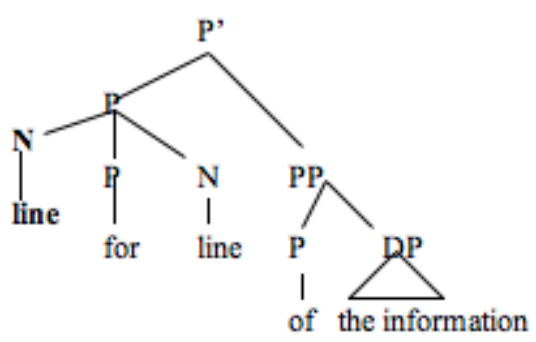

Another case of reanalysis is the following:

(49) spoonful by spoonful of soup (internet source)

Here, spoonful by spoonful is similar to quantifiers like $a$ lot of. It is a determiner and soup is the head $\mathrm{N}$ subcategorized by that determiner. The reanalysis mechanism is similar to the preceding example line for line, but in this case, spoonful is not the head $\mathrm{N}$ of the whole nominal, contrary to line above, it is a D:

(50)

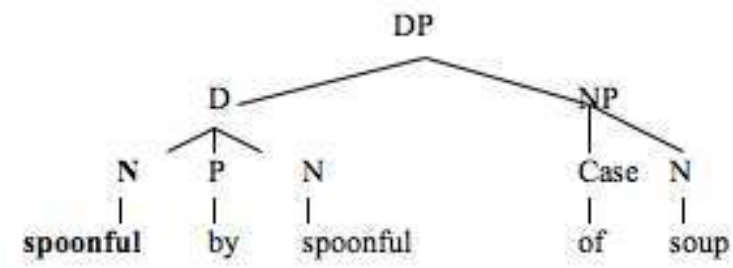

Let us now turn to a few properties of NPN.

\section{Syntactic and lexical absolute constructions and the binding theory}

Consider the following syntactic absolute construction:

(51) Jules et Jim se tiennent la main sur l'épaule.

Jules and Jim are standing the hand on the shoulder

'Jules and Jim are standing with their hands on their shoulders.' 


\section{mental representations of referents and their images, that the binding principles apply} between things and their images. For example, even though the referents are not the same (Jules and his reflection), it is impossible to describe John watching himself in the mirror with:

(54) *Jules is watching Jules. The same holds of the images of body parts. B
image of the eyes and the other to the real ones:

$(55)^{*}$ Jules se regardeles yeux dansles yeux. Jules REFL is watching the eyes in the eyes

'Jules is watching himself the eyes in the eyes.'

This absolute small clause has two possible readings, a reflexive one, in which the two Now, when the two body-parts are mentioned by the same noun, the reflexive meaning is no longer available.

(52) a. *Jules se tient (la) main dans la main/le pied contre le pied, anxieux. Jules is standing (the) hand in the hand/the foot against the foot nervous 'Jules is standing hand in hand/foot against foot, nervous.'

b. Jules et Marie se tiennent (la) main dans la main.

Jules and Marie are standing (the) hand in the hand 'Jules and Marie are standing hand in hand.'

crossed, or with one foot against the other, but it is not possible to describe these postures with an absolute construction, as in (52a). As for (52b), it can only have the reciprocal interpretation, not the reflexive one.

theory as applying to the second occurrence of the body-part in the small clause, la main. Even if la main does not mention the same thing in its two occurrences, it mentions the same body-part. Body-parts have a curious referential status. For instance, in the following sentences, it does not make sense to wonder which of the hands is raised, or which of the cheeks receives the kiss, even if his hand or the cheek are definite nominals:

(53)a. John raised his hand.

b. He pecked her on the cheek. names a type rather than a token. It names a particular body-part, instantiated with two tokens. Another occurrence of lamain will have the same meaning, that particular bodypart of a certain person. By Principle C, lamain may not c-command lamain when these DPs have the same reference, namely when they refer to the same body-part, that is to say when they belong to the same person, as in (52a). Otherwise, they do not have the same reference, and there is no problem with Principle $C$, as in (52b) in its reciprocal interpretation.

The conclusion of this discussion is that, in the syntactic absolute construction, the nominals naming the body-parts are subject to the binding theory and prevent reflexive interpretations. 
Considering the lexical absolute NPN construction, we observe the same thing:

(56) *Jules is standing nose against nose. ${ }^{25}$

(57) *Jean se tient devant le miroir nez contre nez.

Jean REFL is standing before the mirror nose against nose

'John is standing before the mirror, nose against nose.' $\mathrm{C}$, and, in this particular case, the form face à face too, which can only describe a reciprocal relation between two symmetric individuals, for the Principle $C$ reason I have just given above for syntactic expressions like la main dans la main, 'the hand in the hand'. Then, as a learned form, it is no longer processed compositionally and $\mathrm{N}$ no longer refers to a face. The expression is apprehended holistically with the obligatory reciprocal meaning it has acquired, given Principle $C$. Then, reciprocal expressions require the expression of two individuals in the clause. So, (59) is excluded for the same reason as a sentence with an argument that is lacking, such as the following:

(60) *With that drug, John at last met. Interestingly, the second argument missing in (59) may be a reflexive, as shown in (62), similarly to a sentence like the following:

(61) John at last met himself. 
In that case, the face to face expression is permitted, even if, strictly speaking, the faces belong to the same person:

(62) Henri se tenait face à face avec lui-même.

Henri stood face to face with himself

100 in performance, so face does not refer, and thus does not fall under principle $C$.

101 reflexive situation, (63b). Like face à face, the reflexive argument must be added in order to play the role of the extra participant made necessary by the reciprocal interpretation, (63a):

(63) a. *Devant son miroir, Henri était nez à nez.

Before his mirror Henri was nose to nose

b. Devant son miroir, Henri était nez à nez avec lui-même.

Before his mirror Henri was nose to nose with himself

As for contre, its productivity shows that it is produced on the spot, and hence that it has compositional meaning. On the model of face à face, it is marginally possible to add an argument with avec 'with':

(64) ?Tom est nez contre nez avec Jerry.

Let us consider the reflexive meaning. Without avec, the sentence is bad. Adding avec yields the perception of the subject participant as a doubled person:

(65) *Devant son miroir, Jerry était nez contre nez.

Before his mirror, Jerry was nose against nose.

(66) ( ?)Devant son miroir, Jerry était nez contre nez avec lui-même.

Before his mirror, Jerry as nose against nose with himself.

The addition of himself in this case recalls cases with parler. Se parler 'reflexive + speak' is excluded alone. It is rescued by a tonic pronoun lui-même 'oneself', and in that case the sentence is interpreted as a doubling of the subject participant; the reading is that the participant acts with himself as if that were another person:

(67) *Regarde, Jerry se parle.

Look, Jerry REFL is speaking

(68) Regarde, Jerry se parle à lui-même

Look, Jerry REFL is speaking with himself

This meaning does not arise with face à face avec 'face to face with' or nez à nez avec 'nose to nose with'. I suppose that what happens with contre 'against' is what happens with se parler 'REFL speak': the addition of the tonic reflexive lifts the violation of principle $\mathrm{C}$ by making the same participant be perceived as another person. So, with contre, there indeed is a violation of principle $\mathrm{C}$, but ill-formedness is avoided by the addition of the tonic reflexive.

\section{The super lexical absolute construction}

Parts of this section will be tentative, the purpose of the section being to point to plausible research directions stemming from the analysis of the NPN construction. There exists in French a construction composed of two lexical absolute constructions, which I will coin the "super absolute construction": 
(69) Ils s'éloignèrent, bras dessus bras dessous.

They went away arm over arm under

'They went away, arm in arm.'

Here, two prepositions with opposite meanings are required in order to name a symmetric posture. The whole absolute construction needs to say that each arm is not only on but also under the other one. One small clause alone is excluded:

(70) *Ils sont partis, bras dessus

They left, arm over

The constructions bras dessus and bras dessous do not look like two NPN structures, since there are no nouns after the prepositions dessus and dessous. This is really tangential to the question of the form and interpretation of super absolute small clauses, but, to carry on the discussion, we will assume that these Ps are transitive and that their objects are silent elements whose antecedents are mentioned earlier in the linguistic context (ZribiHertz 1984), so we work with bras dessus $x$ bras dessous $y$.

The super absolute form bras dessus bras dessous describes the symmetric forms of two people's arms. I claim that this construction is formed all at once as the symmetric merging of two coordinate lexical absolute small clauses, bras dessus and bras dessous, themselves the outputs of mirror symmetric merging of the $\mathrm{N}$ around the $\mathrm{P}$ :

(71) [[bras dessus bras] [bras dessous bras]

110 This reads as 'bras sur bras, bras sous bras' 'arm on arm, arm under arm' and it is formed by the synchronic projections of the two small clauses: [ bras sur bras] and [ bras sous bras ].

111 As for the initial numeration of the super absolute small clause, it is plausible to assume that it is $\{\mathrm{N}, \mathrm{P}\}$, that is to say, $\{$ bras, stative locative $\mathrm{P}\}$ and that this numeration projects via repetition symmetry two coordinate small clauses formed with mirror symmetry, yielding the interpretation of the shape of two intermingled arms. Linguistically, the whole structure is formed in one step. That is why I have indicated in the numeration the information of the prepositional word that it be a stative vertical locational $\mathrm{P}$, whereas its lexical realization is left to choice of lexical items, this choice being restricted by the requirement that the Ps express opposites (sur/sous, here, and, as we will shortly see, in/ out): ${ }^{26}$

(72) Double simultaneous symmetric merging:

[ [ bras P bras ][ bras P bras ] ]

The P can be realized with opposites, like dessus and dessous 'over' and 'under'

numeration: \{bras, stative locative $\mathrm{P}\}$

112 Evidence for simultaneous merging of the whole structure and not one small clause after the other is that overt coordination is, to my ear, impossible:

(73) *Ils sont partis, bras dessus et bras dessous.

113 To pursue the study of the super absolute construction, note that, like the simple absolute construction, the super absolute construction may not have a reflexive interpretation. We may say brascroisés 'arms crossed', but not bras dessus bras dessous to describe Jules:

(74) a. Il était là, bras croisés.

He was there arms crossed

b. *Il était là, bras dessus bras dessous.

He was there, arm over arm under 
114 As we saw, Principle $C$ requires that the arms name different types, forcing them to belong to two distinct people. Then the expression gets stored in memory, where it has a holistic reciprocal meaning, making it unable to describe one person only.

115 Tentatively, I will propose two other cases that seem to enter the super absolute construction, though they do not share all the properties of the above, like the fact that they accept overt coordination. For instance, the Old Testament proverb:

(75) oeil pour œil, dent pour dent

eye for eye tooth for tooth

'an eye for an eye and a tooth for a tooth'

116 With the absence of determiners in French and their presence in English, we see that French has construed that expression as a complex word, and English as a syntactic idiom. The expression is a set of two lexical small clauses meaning exchange, merged all at once. This expression starts with the numeration sets \{body-part, pour\}. The two small clauses are juxtaposed, which yields the meaning of coordination, which itself may carry conditional force, which is the case here (see Culicover and Jackendoff 1997). Each small clause is projected in a mirror symmetric fashion, the P meaning a switch of the things ( body-parts) named by $\mathrm{N}$ in each conjunct. In this case, it is the Ns that vary in the two conjuncts. $^{27}$

117 As for coordination, as I mentioned, it is not excluded:

(76) ?Oeil pour oeil et dent pour dent.

'An eye for an eye and a tooth for a tooth.'

I assume that this is because the small clauses name consecutive events, not simultaneous states as with bras dessus bras dessous.

One other expression is the following:

(77) day in day out

It means 'day after day'. It can also be used with an overt coordinator, again coupled with the meaning of consecution:

(78) day in and day out

121 This looks like an instance of the super absolute construction. As with the French super absolute construction, this expression makes sense only if the two small clauses are present, each one containing a preposition with the opposite meaning to that of the other:

(79) *day in

This suggests that the construction is built with symmetry of two elements. If we represent the days on the oriented line of time, with a separating plane between two days, then we may say that one day is 'in' before entering that moment and becomes another day that is 'out' after that, with the metaphor that events enter moments of time as they take place:

(80)

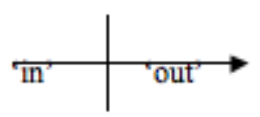

The opposition between in and out gives rise to a plane of symmetry placed across the oriented line of time. Then the thing which is named by the $\mathrm{N}$ is said to be situated across that plane. Merging of $\mathrm{N}$ and $\mathrm{P}$ yields $\mathrm{N}$ as the subject of a lexical small clause the 
predicate of which is the preposition, and symmetric merging of that structure yields two such small clauses, the whole reading being 'day is in, day is out'. In this case, contrary to the analysis given for bras dessus bras dessous, the $\mathrm{P}$ is intransitive. As for the structural projection of this lexical conjoined construction of two small clauses, it starts with the numeration of only two elements \{day, $\mathrm{P}$ naming containment\} which projects in sequence symmetry, with $\mathrm{P}$ realized as the opposites in and out. Sequential symmetry combined with the fact that day does not name any particular day, yields the result that the days are different, multiple and sequential, as with the expressions bumper to bumper or step by step.

\section{Conclusion}

As a conclusion, without loading the theory with new grammatical rules or conditions, this article has attempted to elucidate the NPN formations, and it has shown, first, that the NPN form is lexical, and that it actually corresponds to two constructions. An NPN construction is either a lexical small clause, if $\mathrm{P}$ is the head, or a lexical coordinate structure, if $\mathrm{N}$ is the head. And second, the article has shown that general wellformedness rules of the syntax and the lexicon, combined with and som

etimes explained by, cognitive properties on mental representations, account for the properties of the NPN constructions. This account has drawn on the well-documented fact that cognitive capacities of human beings are rewarded by symmetry. The article has also explained why NPN body-part constructions may not have a reflexive meaning, raising questions on the distinction between performance and competence and it has discovered a super absolute construction.

\section{BIBLIOGRAPHIE}

Aronoff,Mark. 1976. Word formation in generative grammar. Cambridge, MA: MIT Press.

Beck, Sigrid and Arnim von Stechow. 2006. Dog after dog revisited. Ms., Universität Tübingen.

Bresnan, Joan and Sam A. Mchombo. 1995. The lexical integrity principle: evidence from Bantu.

Natural Language and Linguistic Theory 13: 181-254.

Culicover Peter and Ray Jackendoff. 1997. Syntactic Coordination Despite Semantic

Subordination. Linguistic Inquiry 28.195-217.

Fauconnier, Gilles. 1984. Mental spaces. Cambridge, MA: MIT Press. Also, Espaces mentaux. Paris: Minuit.

Goodall, Grant. 1984. Parallel structures in syntax. Doctoral dissertation. University of California at San Diego.

Hanon, Suzanne. 1989. Les constructions absolues en français moderne. Leuven: Peeters. Bibliothèque de l'Information Grammaticale. Series number: 18. 
van der Helm, Peter A. and Emanuel L. J. Leeuwenberg.1996. Goodness of visual regularities: A nontransformational approach, Psychological Review 103: 429-456.

Ivry Richard, Diedrichsen Jörn, Rebecca Spencer, Eliot Hazeltine and Andras Semjen. 2004. A cognitive neuroscience perspective on bimanual coordination and interference. In Interlimb coordination, S. Swinnen \& J. Duysens (eds.). Nowell: MA: Kluwer Academic Publishing. Available on

http://ist-socrates.berkeley.edu/ ivrylab/pdf/idshs_03ip.pdf. Jackendoff, Ray. 1983. Semantics and Cognition. Cambridge, MA: MIT Press.

Jackendoff, Ray. 2006. Alternative minimalist visions of language.Proceedings of the 41the meeting of the Chicago Linguistics Society, Chicago.

Jackendoff, Ray. 2008.Construction after construction and its theoretical challenges.Language 84: 8-28.

Kayne, Richard S. 1984. Connectedness and binary branching. Dordrecht: Foris.

Kayne, Richard S. 2010. Why are there no directionality Parameters? ms. New York University.

Lieber, Rochelle. 1983. Argument Linking and Compounds in English.Linguistic Inquiry 14: 251-286.

Massam, Diane. 1989. Part/Whole constructions in English. In West Coast Conference on Formal Linguistics (WCCFL) 8 (Jane Fee and Katharine Hunt eds.): 236-246.

Matsuyama, Tetsuya. 2004. The $N$ after $N$ construction: a constructional idiom. EnglishLinguistics 21: 55-84. Published by the Linguistic Society of Japan.

Meschner, Franz. 2004. Perceptual-cognitive control of bimanual coordination. International journal of sport and exercice psychology 2: 210-238.

Munn, Alan B. 1993. Topics in the syntax and semantics of coordinate structures. Doctoral dissertation. University of Maryland.

Oehrle, Richard. 1998. Noun after noun. Paper delivered at LSA Annual Meeting.

Pi Chia-Yi, Tony. 1995. The structure of English iteratives. Paper presented at the Annual Conference of the Canadian Linguistic Association, (ACCLA). Paivi Koskinen (ed.). Toronto Working Papers in Linguistics: 434-445. University of Toronto.

Postal, Paul. 1969. Anaphoric Islands. Papers from the Fifth Annual Meeting of the Chicago Linguistic Society. pp. 205-239.

Postma, Gertjan. 1995. Zero-semantics: the syntactic encoding of quantificational meaning. In M. den Dikken and K. Hengeveld (eds.) Linguistics in the Netherlands 1995: 175- 190. Amsterdam: Benjamins.

Ross, John Robert. 1967. Constraints on Variables in Syntax. Doctoral dissertation, MIT. Cambridge, MA.

Rothstein, Susan. 1983. The syntactic forms of predication. Doctoral dissertation, MIT. Published in Bloomington: Indiana University Linguistics Club 1985.

Stowell, Tim. 1983. Subjects across categories. The Linguistic Review. 2/3: 285-312.

Vergnaud, Jean-Roger and Maria-Luisa Zubizarreta. 1992. The definite determiner and the inalienable constructions in French and in English. Linguistic Inquiry: 595-652. 
Williams, Edwin. 1978. Across-the-board rule application. Linguistic Inquiry 9: 31-43.

Williams, Edwin. 1980. Predication. Linguistic Inquiry 11: 203-238.

Williams, Edwin. 1981. On the notions "lexically related" and "head of a word". Linguistic Inquiry 12: 245-274.

Williams, Edwin. 1994a. Remarks on lexical knowledge. In The acquisition of the lexicon, Lila Gleitman and Barbara Landau (eds.). Cambridge, MA: MIT Press.

Williams, Edwin. 1994b. Thematic structure in syntax. Linguistic Inquiry monograph \#23, Cambridge, MA: MIT Press.

Zribi-Hertz, Anne. 1984. Orphan prepositions in French and the concept of null pronouns.Indiana University Linguistics Club. Also: Prépositions orphelines et pronoms nuls. Recherches linguistiques, Université de Vincennes.

I thank Richard Renault for our numerous discussions, and Betsy Ritter and Peter Svenonius for their fine and helpful comments. Lots of thanks to Tarald Taraldsen, Gillian Ramchand and the audience at the Thursday night colloquia series at the Center for Advanced Study on Theoretical Linguistics (CASTL) at the University of Tromsø in September 2008; and Jacqueline Guéron, Ritchie Kayne, Elena Negoita-Soare and the audience at the first Rencontres d'Automne de linguistique formelle (RALFe) conference of the University of Paris 8, 14-16 October 2010.

Many thanks to the two anonymous reviewers for CORELA for their very useful comments.

\section{NOTES}

1. The present article aims at clarifying the data and proposing a general analysis of the two NPN constructions, leaving for further research the refinements needed for each preposition.

2. Jackendoff calls "lexical" all memorized units, whether they have the form of words or phrases. So, the reader should be aware that I am using this term in the traditional sense (Aronoff 1976; Williams $1994 \mathrm{~b}$ or 1981), where lexical means, if derived, formed by rules yielding zero-level forms. Syntax merges these units together. We may memorize words, as well as other linguistic forms. Some of them keep their phrasal properties, like come to terms with, a VP with an open position, and some of them turn into words, like go-between.

3. One should not be confused with the existence of forms like the following: (i) The media are has-been-makers., (ii)They're not fond of take-it-or-leave-it-ness. Here, the phrases has-been and take-it-or-leave-it are converted into words. Then, each of these words may form a compound, as in (i), or may be suffixed, as in (ii).

4. As noted by a reviewer, some compounds may contain a plural N, as in: (i) teeth mark, parks commissioner, sports center. So, it is the absence of the plural form that is indicative of word formation. The reviewer has suggested that in compounds, it could be that the prehead element (say, in orange juice) is not plural because it is treated like a mass noun, in which case it could be analyzed as a full DP, with a zero determiner. This is an interesting possibility, and it is certainly the case that the prehead element names the notion and has no referring status. But in that case, this could be because it has no determiner at all, not even the presumed zero determiner of mass nouns, as in French, for example. In French, in romance compounds, the complement may not have a determiner either, and French does not have the zero determiner: (ii) clair de lune / *clair de la lune // light of moon / 'moonlight'; light of the moon/ the-moon-light'

5. Such small clauses are fine under other verbs, like préférer 'prefer', and that is because in that context the small clause may have a transitory reading: (i) Dans les photos, on le préfère les yeux noirs. / In pictures, people prefer him the eyes black. 
6. For information, small clauses denoting permanent properties of the body-part may not either appear under seem and become verbs: (i) *Jean semble/parait/est devenu les cheveux longs. / Jean seems/looks/became the (his) hair long

7. (13g) is a difficult sentence to assess; it sounds neither perfect nor fully bad. However, modification is impossible if the head noun is not ceux. I do not know why this is so: (i) *Les employés les mains en l'air ont été déplacés. Employees the (their) hand up have been moved away / 'The employees with their hands up have been moved away'

8. An anonymous reviewer suggests that this could be because of the evidential meaning of copular seem and appear, in the sense that the property /face to face/, as opposed to properties like /upset/, is not derived from clues. This is a good point, for example, with added context, seem face to face sounds less bad. But still, it is not perfect: (i) ??In this picture, the actors seem face to face, but the woman is at the front and the man at the back.

9. My view is that of traditional morphology, so words used as zero-level forms in syntax may themselves be formed with words.

10. The head of a word is the morpheme that projects up. See Williams (1981).

11. Minimalist syntax relates the subject and its predicate with a functional head, but it is not clear that such heads should be postulated inside words. I will assume that in compounds there must be a sister relation between subjects and predicates, not mediated by a functional head, as in GB-type small clause structures.

12. I cannot fully exclude forms like main contre front 'hand against forehead' which appear in litterature. I suppose that they are Romance compounds, similar to cul par-dessus tête.

13. I remind the reader that small clauses have been argued by Stowell (1983) and subsequent work in the literature to be headed by the head of the predicate of the small clause. For instance, a small clause like $\left.\left[\text { Albert }\left[\text { tranquille }_{\mathrm{A}}\right]_{\mathrm{AP}} \text { ] is an AP: [ Albert [ tranquille }{ }_{\mathrm{A}}\right]_{\mathrm{AP}}\right]_{\mathrm{AP}}$.

14. The question of the universality of the binary branching word order structure $\mathrm{S}-\mathrm{H}-\mathrm{C}$ (specifier-head-complement) has been tackled recently in Kayne (2010). There, Merge does not form a set, $\{\mathrm{H}, \mathrm{C}\}$, but an ordered pair, $<\mathrm{H} \mathrm{C}>$, according to the hypothesis that probe-goal search should have the same directionality as parsing and production. That is to say, the head, which is a probe, must be to the left of the complement, the goal, because this order respects the order of parsing and production. As for the order of the specifier on the left of the head, it derives from the fact that the specifier merges with the head too, and that, when two elements merge with a head, conditions on Merge conspire to the result that these elements must occur on opposite sides of that head. For coordinate structures, Munn (1993) has claimed that they are asymmetrical adjunction structures, in which the conjunct is adjoined to the right of the head.

15. I am not saying that this is the case with all mental tasks, but some tasks, such as argumentpredicate saturation, can only be done in a stepwise manner. It is the case with addition, for example. I am not saying either that we cannot process any two mental tasks at the same time.

16. In actual performance of synchronic bimanual movements toward a target, psychologists have found that interference of one movement onto the other is frequently observed during bimanual movements if the two hands perform non symmetric actions. They have also shown that certain constraints are absent when bimanual reaching-movements are made to visual targets, that is to say, targets that are pointed to, as opposed to targets indicated with a symbol ( Ivry, Diedrichsen, Spencer, Hazeltine and Semjen 2004), but this second point may not bear on our discussion, it just asks for caution on the statement of the easiness of symmetry in manual tasks.

17. Recent work in the psychology and neurology of bimanual coordination has claimed that the preference for symmetry and synchrony and the various constraints imposed on bimanual tasks pertain to cognitive constraints rather than motor control ones. See Ivry et al. (2004) and Meschner (2004). 
18. One may wonder whether we must conclude that the P-unit with the complement on the left violates the left-to-right requirement on the head-complement relation. If we assume that the directionality requirement derives from cognitive constraints on computation, it does not, precisely because it is an action done in symmetry, a cognitive ability overriding the basic one. Moreover, symmetry is what makes the structure read both ways: symmetry lifts the directionality requirement and I suppose that it not only allows but forces reading from right to left. I will suppose that the left-hand side $\mathrm{N}$, which surprisingly occurs before its head, is in a head-to-complement relation by virtue of being produced by symmetry. It is not computed via the probe-to-target (head to complement) relation, because it is obtained through an action done in symmetry, but, semantically, it results in the head-complement relation of its twin PN. That is precisely the content of the claim that the NPN forms are able to overstep the universal and compulsory antisymmetry of syntax and semantics. Thanks to Elena Negoita-Soare for raising that question. See section 10 for more on that hypothesis.

19. Additionally, the modified DP referring to the individual must be present in the clause, whether the small clause is lexical or syntactic. Below are two small clauses, one lexical and one syntactic, and they behave the same, they require the mention of an individual who they describe. These sentences are excluded because the mention of the individual is lacking: (i) *Il y a eu un départ, dos à dos. (lexical small clause) / There has been a departure, back to back / 'There was a departure, back to back.'; (ii) *Il y a eu une dispute au match, la tête dans le ventre. (syntactic small clause) / There has been a fight at the match, the head in the stomach / 'There was a fight during the match, the head in the stomach.'

20. I thus do not adopt Munn's (1993) analysis.

21. Jackendoff (2008) notes that another property of after and upon is that it is possible to iterate them: (i)a. day after day after day / b. book upon book upon book. We could think that this is a property of coordinate structures, but by may be iterated and it forms a small clause, not a coordinate structure: (ii) Eleven teen-friendly projects in three skill levels build confidence step by step by step. (internet source). This means that the possibility of iteration depends on semantics, and that it is possible whenever there is a meaning of succession. All the NPNs that are interpreted as a succession of same things involve sequential symmetry, and sequential symmetry is a possibility offered in principle to all NPNs, whatever the P. For example, a small clause structure like nose to tail is interpreted with sequential symmetry.

22. If consecution is a property of events rather than individuals, then that means that after and upon have the force of distributive operators taking clausal scope. I leave this question open. See Beck and von Stechow (2006), Oehrle (1998), Postma (1995) and Pi Chia-Yi (1995) for other properties of that construction.

23. For example, French disallows it, which may indicate that modification is indeed an unexpected property: (i) *jour après mauvais jour.

24. Some occurrences seem possible: (i) Flower a step-by-step of giantfrom our next tutorial Gorgeous chiffon hair. (internet). But that is because NPN here is a coordinated noun, complement of the verb flower, not a small clause.

25. There are forms like the following, which do not sound bad: (i) He was there, with his hands steepled, finger to finger. That is because finger to finger here modifies, not the subject he, in which case the sentence should be ruled out, but the nominal his hands. There are thus two bodies, the two hands, and finger to finger has a reciprocal interpretation: "finger of left hand to finger of right hand and vice versa", with no coreference between the two fingers. Thanks to Ritchie Kayne for bringing up this point.

26. I suppose that the fact that the P may be realized by two different words may be explained by the easiness of the mental association of opposites. The same seems to hold with the nouns. In forms in which the nouns are not the same, they name opposites, as with head to tail or nose to tail. Such expressions deserve elucidation. They do not have an initial preposition, so they look like 
NPN constructions rather than Romance formations like (with)head over heels or (from) floor to ceiling. However, they use two different nouns, so, following the logic of the article, they should be ill-formed, unless we suppose that this expression starts with a numeration like \{body-part, to \}, with a similar condition on the $\mathrm{N}$ as that pertaining to the prepositions, that of being opposites. 27. That the Ns are not opposites is a problem for my claim that symmetric merging necessitates opposites when the Ns are different. That is one of the reasons I am cautious about such constructions. However, I said earlier that, if opposites may realize one $\mathrm{N}$, it is because opposites form pairs of words that are easily mentally associated with one another. It is possible that different parts of a face are easily mentally accessed too, even if we cannot speak of opposites there.

\section{RÉSUMÉS}

Cet article propose une analyse des mots de la forme NPN, dont certains sont des propositions réduites et d'autres des noms coordonnés. En effet, dans ce travail, je montre qu'il y a deux classes de mots NPN, et non pas une seule, et que ces classes se distinguent en fonction de l'élément qui est le noyau de la construction: si le noyau est $\mathrm{P}$, alors NPN est une proposition réduite (face to face), et si le noyau est $\mathrm{N}$, alors la construction est un nom coordonné (student after student). Un point théorique central posé par l'existence de telles formes est que ce sont des constructions ternaires, et donc qu'elles vont alors directement à l'encontre de la condition universelle sur la binarité des structures (Kayne 1984). Mon objectif sera alors de résoudre la question de cette anomalie. Je proposerai que la condition de Kayne sur les branchements binaires est de nature cognitive. Cette piste permettra de comprendre grâce à quel type d'action mentale des structures comme NPN peuvent être ternaires, et, en passant, de justifier d'une manière cognitivela contrainte signalée par Jackendoff (2008) et attribuée selon lui à une exigence de reduplication, selon laquelle les noms N de la forme NPN doivent être identiques.

The present article bears on the NPN construction (face to face and student after student), investigated in an illuminating way in Jackendoff (2008). It proposes an account of NPN forms in which they are lexical items. Contrary to what is commonly assumed, there are two types of NPNs, depending on whether the head of the construction is P (face to face), forming a lexical small clause, or $\mathrm{N}$ (student after student), forming a coordinate $\mathrm{N}$. One important theoretical point raised by such constructs is that they are ternary structures and thus seem to contradict Kayne's (1984) universal condition on binary branching. I will claim that, if Kayne's principle is cognitive, in that it reflects the working of mental computation, then these ternary constructions, which should be impossible, are indeed possible, but only because there is one specific way for the brain to allow for their formation. Lastly, the article considers a number of properties of NPNs and accounts for them.

\section{INDEX}

Mots-clés : branchement binaire, propositions réduites, mots cordonnés, symmétrie et cognition

Keywords : binary branching, small clauses, coordinate words, symmetry 
AUTEUR

ISABELLE HAÏK

CRISCO, EA 4255 , Université de Caen 